\title{
Experiences in Becoming a Paramedic: The Professional Socialization of University Qualified Paramedics
}

\author{
A. S. Devenish, M. J. Clark, ML. Flemming \\ Faculty of Health, Queensland University of Technology, Brisbane, Australia \\ Email: scott.devenish@qut.edu.au
}

Received 9 February 2016; accepted 3 May 2016; published 6 May 2016

Copyright (C) 2016 by authors and Scientific Research Publishing Inc.

This work is licensed under the Creative Commons Attribution International License (CC BY). http://creativecommons.org/licenses/by/4.0/

(c) (i) Open Access

\begin{abstract}
In this article, the professional socialization of university educated paramedics from the United Kingdom and Australia is discussed using the anticipatory, formal and post-formal phases of socialization. Participants for this research were from universities and ambulance services in Australia and the United Kingdom, and the data were collected and analyzed by qualitative methods. The anticipatory, formal and post-formal phases were deemed to be relevant to the professional socialization of university paramedics. However a fourth phase, called the post-internship phase was identified which better accounted for the paramedic training and practice model. The findings from this research led to the development of a four phase model of professional socialization to describe the experiences of university educated paramedics making the transition from university students to qualified paramedics.
\end{abstract}

\section{Keywords}

Professional, Socialization, Paramedic, University, Transition

\section{Introduction}

Professional socialization is the process by which people obtain the values, attitudes, knowledge and culture of a profession (Howkins \& Ewens, 1999; Merton, Reader, \& Kendall, 1957). While the professional socialization of medical doctors, allied health professionals and nurses has been well canvased in the literature (Anderson \& Bell, 1998; Becker, Hughes, Geer, \& Strauss, 1961; Chipchase et al., 2006; Davis \& Olesen, 1964; Dinmohammadi, Peyrovi, \& Mehrdad, 2013; Goode, 1960; Tradewell, 1996; Tryssenaar, 1999; Tryssenaar \& Perkins, 2001), there are few studies investigating the professional socialization of paramedics. The reasons for this lie possibly 
with the relatively recent transition of paramedic education in Australia and the United Kingdom from an inhouse vocational apprenticeship model of training to a pre-employment university degree qualification. This article discusses the development of a model which specifically accounts for the professional socialization of university educated paramedics from Australia and the United Kingdom and utilizes the anticipatory, formal and post formal phases of professional socialization as a framework (Devenish, 2014; Higgs, 2013; Cant \& Higgs, 1999; Lamdin, 2006; Shuval \& Adler, 1977).

\section{Background}

\subsection{University Qualifications for Paramedics}

The last two decades have seen a steady progression toward university qualifications for paramedics in Australia and the United Kingdom (Balon-Rotheram, 2003; Battersby, 1993; Donaghy, 2008; Fawcett \& McCall, 2008; Gregory, 2006; Kilner, 2004; Lord, 2003; McDonell, 1994; Raynovich, 2006). Bachelor degree programs in paramedic science commenced in Australia and the United Kingdom during the mid to late 1990s (Carney, 1999; Lord, 2003). In more recent years there has been a rapid expansion of university paramedic programs in both countries.

\subsection{Professionalization of Paramedic Practice}

The transition from an in-house vocational apprenticeship model of training to a bachelor's degree program of study has been an important step in the professionalization of paramedic practice. For example, in 2001 paramedic practice in the United Kingdom became a recognized health profession, with paramedics being required to register with the Health Care Professions Council (HCPC) (Emms, 2010; Whitmore \& Furber, 2006; Woollard, 2009). However, in Australia, paramedics are currently not registered and are viewed as emerging health professionals (O’Meara, 2011, 2012; O’Meara \& Furness, 2013; Sheather, 2009). Although national registration has been approved by the Council of Australian Governments (COAG), it is not expected to take place until 2017 at the earliest (COAG Health Council, 2015). In the interim, the South Australian and Tasmanian Governments have protected the paramedic title through government legislation in an attempt to promote patient safety (Larsen, 2013). New entrants to the paramedic discipline in these Australian States must complete a bachelor's degree in paramedic science prior to obtaining employment.

The new (United Kingdom) and emerging (Australia) professional status of paramedics has been accompanied by a shift away from an organizational socialization process to a professional socialization process. Unlike professional socialization, organizational socialization is concerned with the tactics used by people in an organization to teach new employees about their position, status and role in the workplace (Jones, 1986; Van Maanen, 1978). Conversely, this article presents a theoretical model explaining how people learn the values, behaviors and attitudes necessary to become paramedics through professional socialization.

\section{Professional Socialization Models}

To date there is small body of knowledge examining the professional socialization of university educated paramedics (Devenish, 2014; Devenish, Clark, Fleming, \& Loftus, 2012; Devenish, Clark, \& Fleming, 2014; Devenish, Clark, Fleming, \& Loftus, 2010; Huot, 2013; O’Brien, Moore, Dawson, \& Hartley, 2014; Thompson, 2015). However, there is a body of literature about the professional socialization in other health professions like medicine (Becker et al., 1961; Conrad, 1988; Coombs, 1978; Haas \& Shaffir, 1987; Hafferty, 1988; Pitkala \& Mantyranta, 2003), allied health (Higgs, 2013; Cant \& Higgs, 1999; Tryssenaar, 1999; Tryssenaar \& Perkins, 2001) and nursing (Boychuk Duchscher, 2008, 2009, 2012; Boychuk Duchscher \& Cowin, 2004; Gerrish, 1990, 2000; Kramer, 1974; Owens, Turjanica, Scanion, Williamson, \& Facteau, 2001) which may hold relevance to paramedic practice. Although there are a number of theories and models of professional socialization, a three stage model, namely the anticipatory phase, formal phase and post-formal phase of professional socialization has been applied to the medical, allied health and nursing professions (du Toit, 1995; Cant \& Higgs, 1999; Howkins \& Ewens, 1999; Lamdin, 2006; Maclellan, Ly, \& Gingras, 2011; Shuval \& Adler, 1977; Simpson, 1967). Thus these three phases of professional socialization were tested against the paramedic context.

The anticipatory stage (Figure 1 ) is where the individual forms stereotypical preconceptions about the profession during childhood and early adulthood (Higgs, 2013; Cant \& Higgs, 1999; Lamdin, 2006; Shuval \& Adler, 


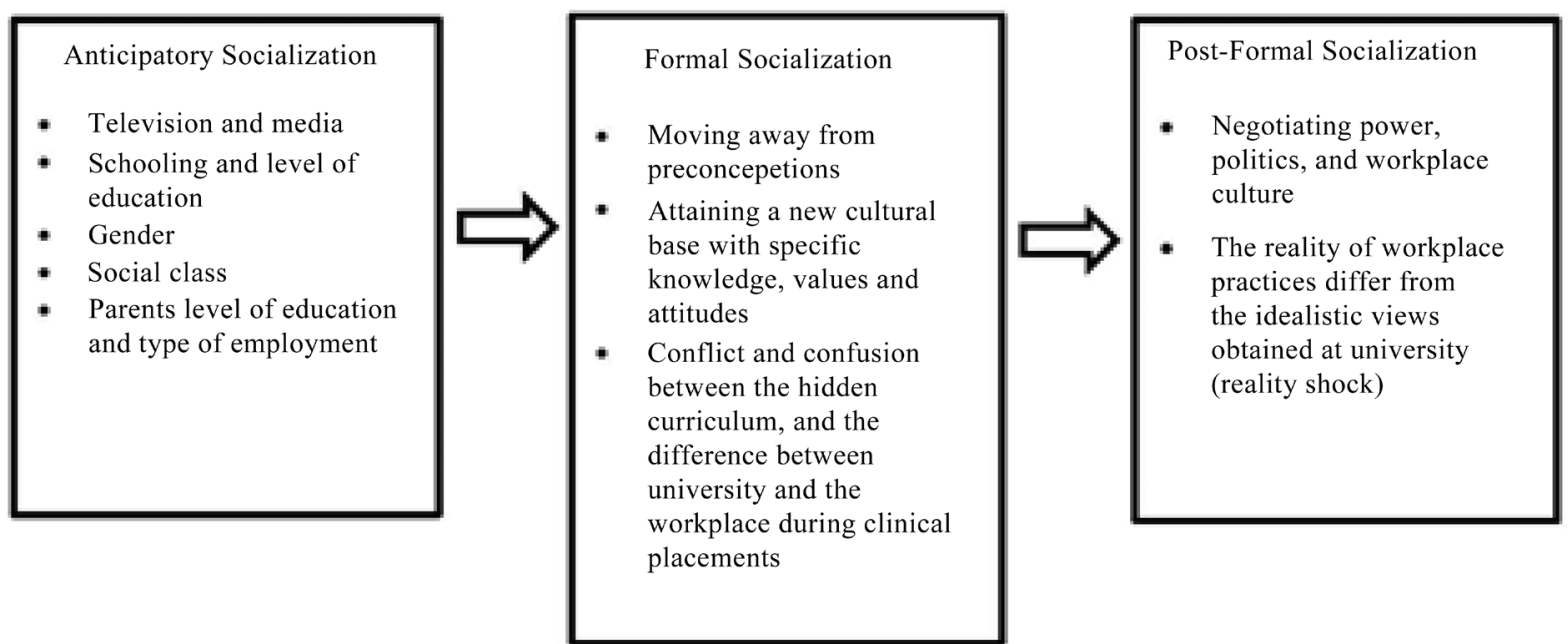

Figure 1. The anticipatory, formal and post-formal phases of professional socialization. developed from the writings of Cant, R., \& Higgs, J., (1999) Professional socialisation in educating beginning practitioners. In J. Higgs and H. Edwards (Eds.), Educating beginning practitioners: Challenges for health professional education (pp. 46-51). Oxford: butterworth-heinemann.

1977). These preconceptions are developed through observation, television, other forms of media and input from family and friends (Devenish, Clark, Fleming, \& Loftus, 2011; Cant \& Higgs, 1999; Lamdin, 2006).

The formal stage (Figure 1) occurs when the individual further changes their perceptions about the profession while undertaking university studies, and completing clinical placements in the workplace (Devenish et al., 2012; Cant \& Higgs, 1999; Shuval \& Adler, 1977; Thornton \& Nardi, 1975). The formal stage heralds the transition toward obtaining a deeper level of understanding about the profession and developing a new cultural base while undergoing tertiary studies at university (Cant \& Higgs, 1999; Lamdin, 2006; Shuval \& Adler, 1977). The post-formal phase (Figure 1) focuses on the transition from university student to professional. In this phase, graduates are required to negotiate workplace culture and politics while they adjust to their new professional roles (Devenish et al., 2012; Cant \& Higgs, 1999; Lamdin, 2006; Shuval \& Adler, 1977).

\section{Methods}

\subsection{Methodology}

In this study, qualitative methods based on the work of Charmaz (2006) and Saldana (2013) were used to guide the data collection and analysis. It is important to note that grounded theory as an "off-the-shelf" inductive process (Charmaz, 2012) was not employed in this study. Instead, we used a deductive model of analysis to test an existing professional socialization model against the paramedic paradigm. In this research we utilized qualitative methods such as semi-structured interviews to collect the data and analysis techniques such as theoretical sampling, memos, field notes, and first and second round coding (Charmaz, 2006; Saldana, 2013).

\subsection{Ethics}

Human research ethics approval was obtained through Charles Sturt University; Queensland University of Technology; and the University of Hertfordshire as well as from several of Australia's larger ambulance servicesand United Kingdom National Health Service Ambulance Foundation Trusts from which the research participants came.

\subsection{Participants}

Participants were recruited through face to face presentations at universities, and through ambulance research institutes. The participants $(n=34)$ were divided into three main cohorts (Table 1$)$. Cohort one participants were about to complete their bachelor degree studies in paramedic science. Cohort two were six months in to their 
Table 1. The Gender and location of participnats recruited for this study.

\begin{tabular}{|c|c|c|c|c|c|c|c|}
\hline \multirow{3}{*}{ Research Cohorts } & \multicolumn{7}{|c|}{ Participants Recruited } \\
\hline & \multicolumn{3}{|c|}{ Male } & \multicolumn{3}{|c|}{ Female } & \multirow{2}{*}{ Total Number } \\
\hline & Aus & UK & Total & Aus & UK & Total & \\
\hline $\begin{array}{l}\text { Final Year at } \\
\text { University }\end{array}$ & 4 & 2 & 6 & 6 & 3 & 9 & 15 \\
\hline $\begin{array}{l}\text { Six Months into the } \\
\text { Internship Year }\end{array}$ & 1 & 5 & 6 & 4 & 0 & 4 & 10 \\
\hline $\begin{array}{l}\text { Qualified or } \\
\text { Registered } \\
\text { Paramedics }\end{array}$ & 2 & 3 & 5 & 2 & 2 & 4 & 9 \\
\hline Total & 7 & 10 & 17 & 12 & 5 & 17 & 34 \\
\hline
\end{tabular}

internship year, and cohort three had completed their internship year and were now qualified (Australia) or registered (United Kingdom) paramedics.

\subsection{Data Collection and Analysis}

Participant interviews ranged from 30 to 60 minutes in length, and interviews were transcribed. The data analysis consisted of first and second round coding (Saldana, 2013). The first round of data analysis involved lumping the data (Dey, 1993) through holistic coding to identify the main codes, followed by line-by-line coding (Saldana, 2013), which broke the holistic codes into sub-codes and sub-sub codes. The second round of data analysis consisted of focused coding, where codes were rearranged in a hierarchy to fit under the main code headings which came from the professional socialization model that formed the theoretical framework for this study (Charmaz, 2006; Saldana, 2013). During the coding of the data, field notes and the professional socialization literature were referred to when developing memos.

\section{Results}

\subsection{Anticipatory Socialization}

Research about anticipatory professional socialization addresses the formation of preconceptions prior to studying at university (Devenish et al., 2010; Higgs, 2013; Cant \& Higgs, 1999). These preconceptions are based on socialization agents such as the influence of media and television, the level of an individual's schooling and education, their gender and social class, and parental level of education and type of employment (Devenish et al., 2010; Higgs, 2013; Cant \& Higgs, 1999). Furthermore the literature breaks anticipatory socialization into childhood and adulthood socialization (Cant \& Higgs, 1999; Jablin, 2001; Kramer, 2010; Van Maanen, 1976). The results from this study relating to the anticipatory socialization of paramedics (Figure 2) suggest that socialization agents in both childhood and adulthood were very similar.

However, during early adulthood, the study participants were able to utilize higher levels of reasoning, research and decision making when building preconceptions about paramedic practice. The results confirmed many of the findings in the literature about the development of professional preconceptions (Cant \& Higgs, 1999; Jablin, 2001; Kramer, 2010; Van Maanen, 1976). For example, television and the media were powerful socialization agents in both childhood and early adulthood (Cant \& Higgs, 1999). In particular, television depicted the high acuity "life saving" aspects of paramedicine when these cases actually make up the minority of the ambulance case-load (Williams, Devenish, \& Stephens, 2012). The views of family and friends at university studying a health related discipline were also found to be important in building preconceptions about paramedic practice. Of importance, family members working in health professions or emergency services appeared to provide a more realistic view of paramedicine compared to television and media portrayals. Conversely, the results indicate that university paramedic students portrayed an unrealistic interpretation of paramedical work. It was commonly reported that preconceptions were developed through observing ambulances responding to an emergency case, and through patient-paramedic encounters (Devenish et al., 2010). Preconceptions were also developed through experiencing a family tragedy (Devenish et al., 2010). An important finding relates to the role of voluntary 


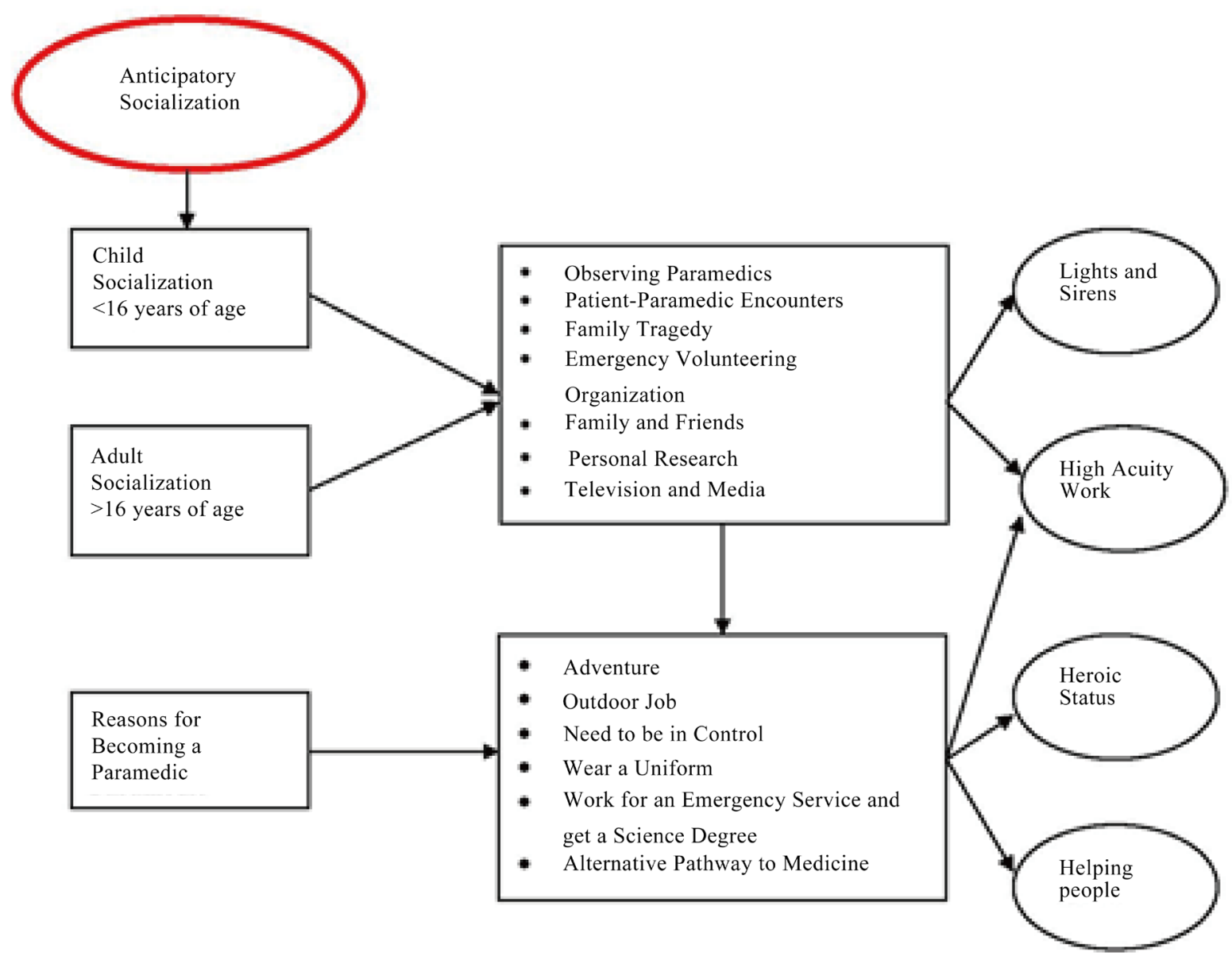

Figure 2. The anticipatory phase of paramedic professional socialization.

emergency service organizations in shaping preconceptions about paramedicine. For example, many participants worked as volunteers for St Johns Ambulance, rural bush fire brigades, volunteer rescue associations and surf lifesaving clubs. Compared to the stereotypical image of paramedics displayed through television and media, the results indicate that working for volunteer emergency organizations led to the development of more realistic preconceptions about paramedic practice.

The decision to become a paramedic was significantly informed by the preconceptions about paramedic practice developed during childhood and adulthood anticipatory socialization. The heroic status of paramedics was a common reason for wanting to join the profession. In particular, the heroic status of a paramedic was linked to wearing an emergency service uniform. Being a paramedic was also viewed as an alternative to joining the military. Others sighted a perceived autonomy associated with paramedic work, believing it to be of an adventurist nature. Thus avoiding an office job or being able to avoid working on a hospital ward was a priority for these participants.

\subsection{Formal Professional Socialization}

Current research on the formal phase of professional socialization indicates that university students encounter a transition away from their initial preconceptions towards the attainment of a new cultural base with an accompanied professional knowledge and skills base (Cant \& Higgs, 1999). Furthermore the literature refers to confusion created by mixed messages encountered from both the formal and hidden curriculums, and from clinical placement experiences in the professional workplace (Higgs, 2013; Cant \& Higgs, 1999). The results from this study confirmed these findings (Figure 3).

Paramedic students had their preconceptions challenged by senior paramedics from an ambulance service who 


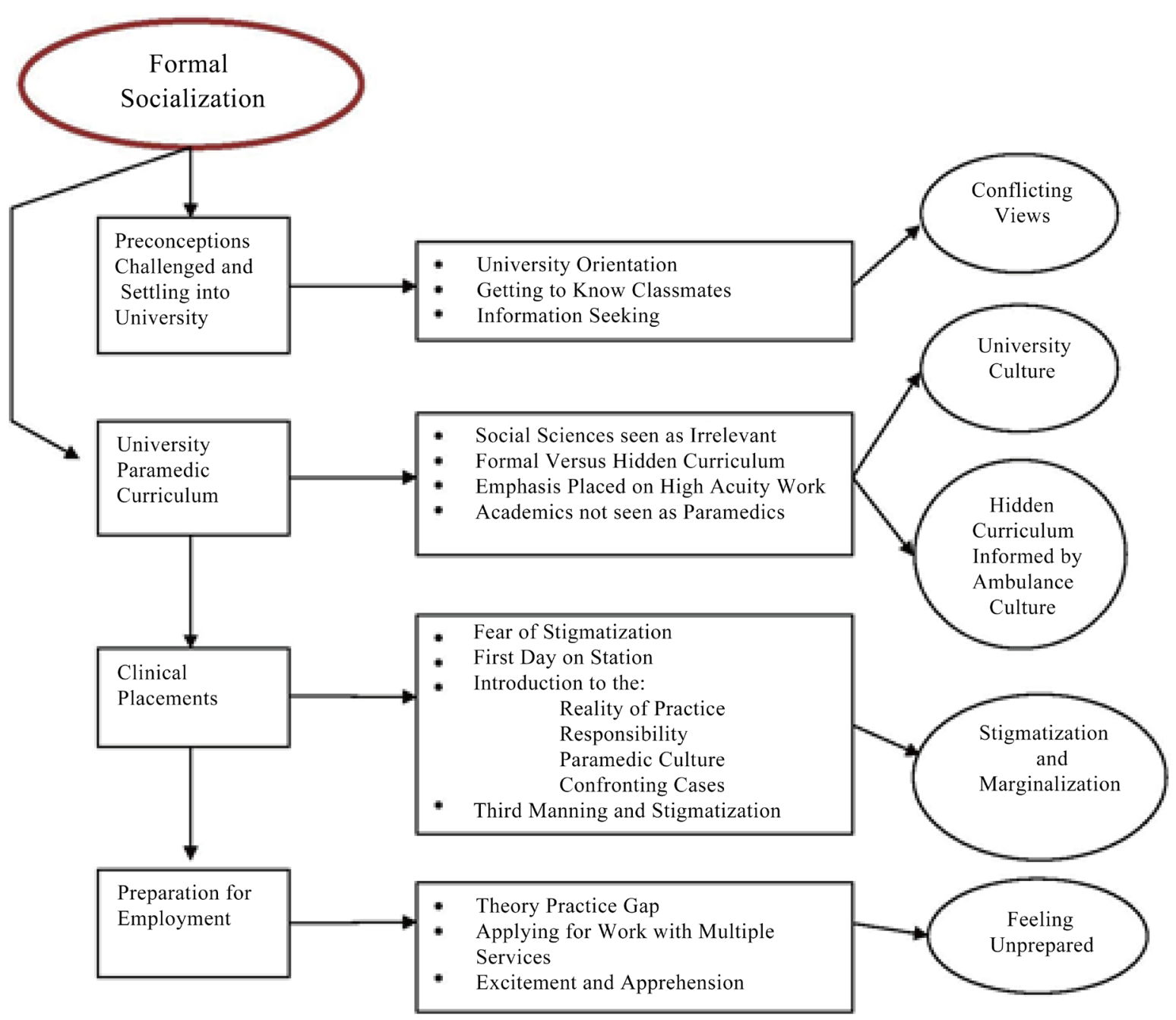

Figure 3. The formal phase of paramedic professional socialization.

spoke at university orientation week, or on the first day of classes (Devenish et al., 2012). The information presented in these sessions, in most cases, outlined a realistic perception of paramedic practice, and challenged the anticipatory preconceptions that ambulance work was all about saving lives and traumatic emergencies. The early involvement of the profession in paramedic programs might indicate a collaborative working relationship between ambulance services and universities. However it might be a remnant from the old apprenticeship inhouse training model where the ambulance commissioner addressed new recruits on their first day of employment. After having their preconceptions challenged, students began an information seeking process to better understand the role of a paramedic. The presence of information seeking found in this study confirms the findings in the professional socialization literature (Finkelstein, Kulas, \& Dages, 2003; Morrison, 1995; Morrison, 1993). The results from this research study indicate that many students do not appreciate the social sciences component of the paramedic curriculum, preferring to concentrate on traumatic emergencies and cardiac arrest. The lack of appreciation for social science subjects in the paramedic curriculum confirms similar findings in the literature (Clark, 2009; Hallikainen, Vaisanen, Rosenberg, Silfvast, \& Niemi-Murola, 2007; Mallinson, 2011; Williams \& Boyle, 2008; Williams, Brown, \& Boyle, 2012; Williams, McCook, et al., 2012; Willis, Williams, Brightwell, O'Meara, \& Pointon, 2010). Other professional socialization agents present in the formal phase were encounters with paramedic tutors, lecturers and senior undergraduate paramedic students while at university and on-road paramedics during clinical placements. Through clinical placements, students observed the ambulance culture first hand, and learned about the responsibilities associated with being a paramedic. Confronting cases were also encountered, as students began to learn resilience skills through observing their mentors. A stigmatization to- 
wards university students on clinical placements was evident from the findings because the majority of the paramedic workforce was trained through an in-house vocational apprenticeship model, and possibly viewed university educated paramedics as a threat. Marginalization during placement (Boychuk Duchscher \& Cowin, 2004) was evident because students were outside of their day-to-day university culture, and had not yet been accepted into the ambulance culture. Experiences during clinical placements led to a reported theory-practice gap, as some practices and equipment used by paramedics in the on-road environment differed from that which was available at university. Furthermore, experiences from clinical placements possibly had a direct impact on the application for employment process, where students applied for other services as a result of encountering stigmatization.

\subsection{Post-Formal Professional Socialization}

The post-formal phase is where graduates learn to negotiate power, politics and workplace culture (Higgs, 2013; Cant \& Higgs, 1999), and encounter a reality shock where the workplace appears to be different from expectations developed at university (Boychuk Duchscher, 2009, 2012; Kramer, 1974). The results from this study confirm these findings (Figure 4). During the post-formal phase, graduate paramedics made the transition from

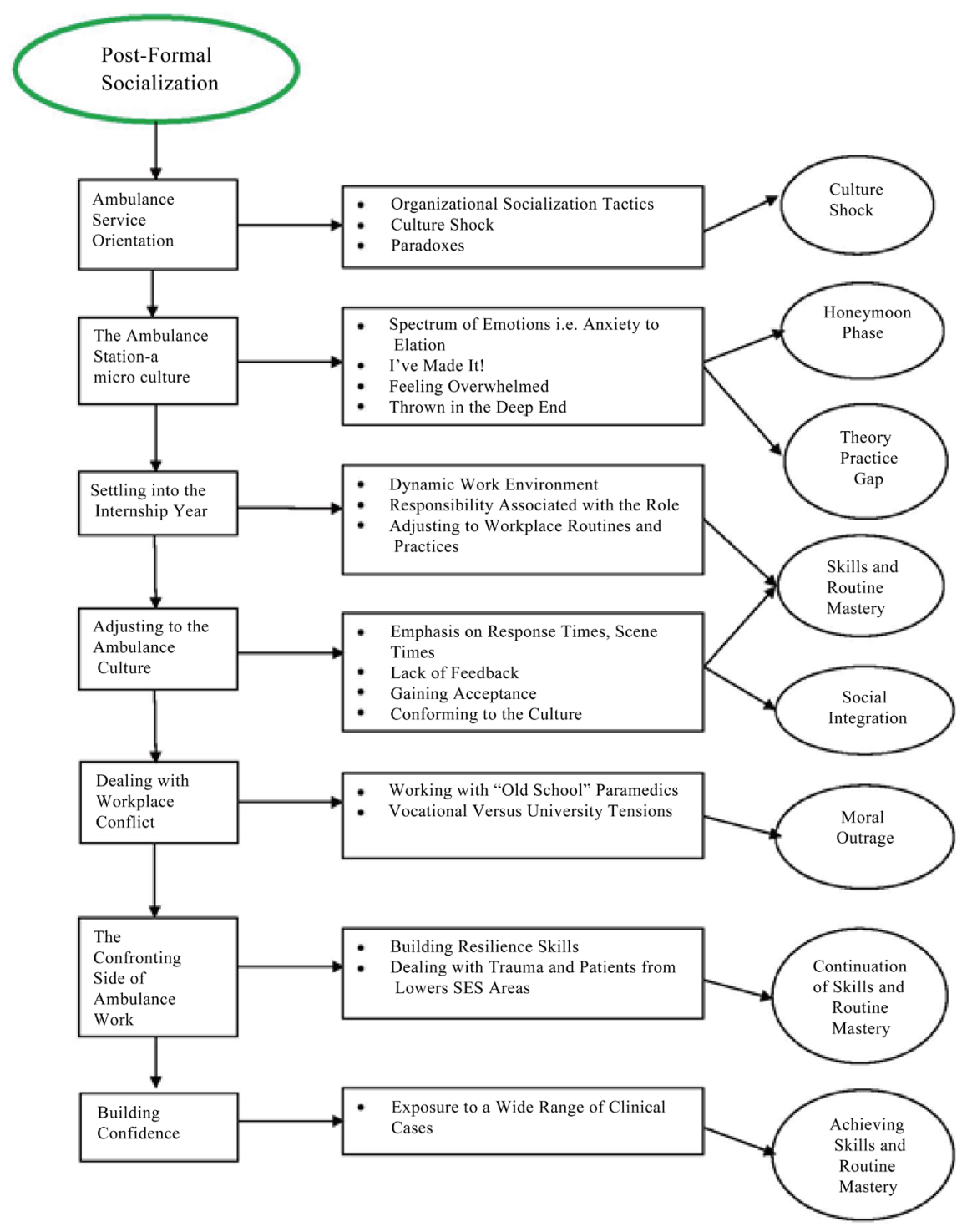

Figure 4. The post-formal phase of paramedic professional socialization. 
university student to practicing paramedic intern, and were required to complete a professional year of employment. Interns were initially required to undertake an orientation program with an ambulance service, which consisted of an introduction to the service's clinical guidelines, and an overview of the general day to day running of ambulance operations. During the orientation course, interns were exposed to the paramilitary culture of paramedicine, such as a militaristic chain of command and rank insignia on epaulets. Many interns reported experiencing an initial culture shock, as the ambulance culture was vastly different to the university environment. However, interns felt comforted by the presence of their university friends, and many described the process to be an extension of their university course. Thus a paradox appeared between the intense uncomfortable nature of a culture shock and the reassuring presence of familiar classmates.

When transitioning from the orientation program to the on-road station environment, interns encountered another marginal zone (Boychuk Duchscher \& Cowin, 2004), where they were outside the comfort of the university culture, and had not yet been accepted into the ambulance culture as equals. Interns reported various experiences when arriving on station for the first time as an employee. For example, some felt ostracized and reported the continuation of the stigmatization encountered during university clinical placements. Others felt more included and accepted compared to their experiences during clinical placements as university students. Despite these varying experiences, a honeymoon phase (Kramer, 1974) was observed as interns commonly felt relieved to have finished their university studies and were proud to wear an ambulance uniform. Another notable component to the honeymoon phase was encountering the first a code one lights and sirens emergency case as an employee. It appears as though this phenomenon was seen as a "rite of passage" by many interns, confirming that they had "made it". However the honeymoon phase for many was short lived. Some interns described the experience of being "thrown in the deep end" when placed in the back of an ambulance, on their own, with a critically ill patient early in their internship year. Furthermore, interns became aware of aspects of the ambulance culture where peers judged each other on their ability to perform skills. Thus interns possibly interpreted that the key to gaining acceptance in the workplace was though developing skills and routine mastery (Kramer, 1974). For example, interns began spending more time in the ambulance station training room, and became more aware of workplace routines, such as performing pre-shift car checks, and choosing to treat for the shift and letting the more senior paramedic drive the ambulance. During the skills and routine mastery phase, interns reported their frustration at the cultural lack of positive feedback from supervisors and other staff. It was suggested that feedback was only given after they had made mistakes. Aspects of the ambulance culture such as a professional language, and routine workplace practices were observed and importance was placed on these with a view to fitting in and gaining workplace acceptance. For example, interns spoke of the need to be pessimistic about their job, and to ostracize or be disparaging of ambulance management and the communication center staff in order to be culturally accepted. Others became aware of conflict between university graduates and vocational in-house trainees, and between the "old hands" and new graduates. In addition to managing conflict in the workplace, interns had to try and normalize the confronting nature of some high acuity cases. Resilience techniques adopted by new graduates appeared to be heavily influenced by their mentors and included gallows humor, depersonalization, choosing not to dwell on confronting scenes and developing an emotional bank account (Devenish et al., 2012).

Towards the end of the internship year, interns reportedly experienced improved confidence levels. A possible reason for this could relate to experiencing a wide variety of clinical cases (Lazarsfeld-Jensen, Bridges, \& Loftus, 2011). It might also indicate that interns had achieved skills and routine mastery, and had begun to adjust to the ambulance culture. However, the increase in confidence levels was short lived as interns began to make the transition to qualified or registered paramedic status. Paramedic interns were required to complete a 12 month internship year (professional employment year) before being recognized by the profession as qualified paramedics, despite having completed a bachelor degree. Therefore another phase of professional socialization was deemed necessary, as interns had not been afforded the full responsibility of the paramedic role until qualifying. The new phase of professional socialization is called the post-internship phase.

\subsection{Post-Internship Professional Socialization}

During the post-internship phase (Figure 5), interns made a rapid transition to being qualified paramedics, and were able to wear the qualified paramedic rank on their epaulets. As a result, the newly qualified paramedics entered a second honeymoon phase, as other paramedics and hospital staff afforded them greater respect. However, 


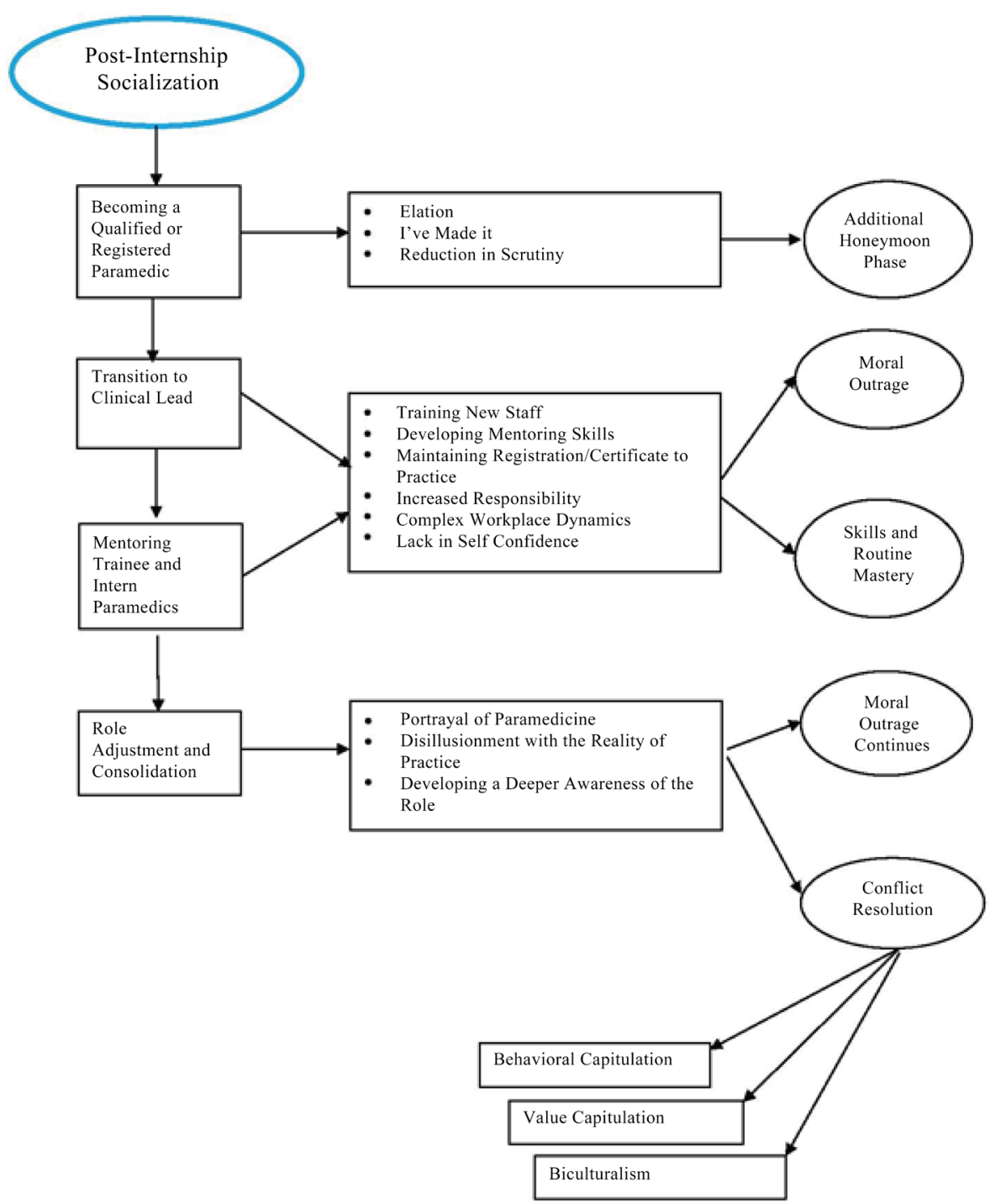

Figure 5. The post-internship phase of paramedic professional socialization.

the second honeymoon phase was again short lived because they had to contend with the added responsibility of being the senior clinician on the ambulance. In many circumstances, they had to train new graduates or vocational apprenticeship trainees who were new to their roles. The results indicate qualified paramedics did not believe they were adequately prepared to mentor new staff, as they were still grappling with adjusting to the role of being a qualified paramedic let alone having to supervise novice practitioners. Others faced new complexities associated with the paramedic role. For example, newly qualified paramedics were required to work with older technicians sometimes with up to 20 years of service who had a lower scope of practice. Thus many found it challenging working as the senior clinician on the vehicle, supervising a crewmate twice their age as well as working in a new area. Qualified paramedics who had not encountered a vast variety of cases during their internship year felt particularly uncomfortable when exposed to high acuity patients, while simultaneously managing new recruits. Despite a small number of qualified paramedics encountering stigmatization because they were university graduates, in general, being a qualified paramedic brought greater levels of acceptance into the ambulance culture.

\section{Discussion}

The results of this study confirmed the presence of an anticipatory phase of professional socialization for para- 
medics. The findings also aligned with the broader literature showing that childhood and adult socialization agents were very similar (Cant \& Higgs, 1999; Jablin, 2001; Kramer, 2010). Childhood views were very stereotypical whereas young adults were seen to develop greater meaning from their experiences despite their preconceptions being heavily influenced by their childhood views.

Working for volunteer emergency organizations appeared to be a significant finding in this research study relating to the anticipatory socialization of paramedics, and one rarely reported in the professional socialization literature. This finding has not been reported in the socialization of nurses, allied health and medical professionals, and thus may be unique to paramedicine. Furthermore, participants who worked for volunteer organizations had less of a stereotypical view of paramedic practice compared to the participants who relied on television and the media. Paramedics who had parents who worked in health disciplines also had less stereotypical views than those who developed preconceptions mainly through television and friends who were student paramedics. For many, the reasons for wanting to be a paramedic were built on unrealistic expectations, such as $24 / 7$ on the go excitement, attending trauma cases and saving lives.

Another significant finding related to paramedicine being an alternative to medicine, or an appropriate pre-medical degree. Although cognitive dissonance (Stone \& Cooper, 2001; Thibodeau \& Aronson, 1992) was observed when some participants justified their decision to be a paramedic instead of a medical doctor, believing that paramedics encountered a work environment which was more challenging than medicine.

The results of this study confirmed the presence of a formal phase of paramedic professional socialization. During this phase a transition away from anticipatory pre-conceptions to a more informed view about the paramedic profession occurred. Socialization agents present in the formal phase were other students, lecturers, tutoring staff, on-road paramedics during clinical placement and the hidden and formal university curriculum. The results in this study confirmed the findings of other authors in relation to the presence of an informal curriculum (Devenish et al., 2012; Devenish et al., 2011; Henderson, 2012; Willis et al., 2010) and stigmatization (Boyle, Williams, Cooper, Adams, \& Alford, 2008; Lord, McCall, \& Wray, 2009; Waxman \& Williams, 2006; Williams, Brown, \& Winship, 2012; Wray \& McCall, 2009) during clinical placements. Furthermore, a theory-practice gap, which appears to be evident from the results, confirmed similar findings reported in the literature (Michau, Roberts, Williams, \& Boyle, 2009; Ross, 2012; Sibson \& Mursell, 2010; Tanner, Knights, \& Strange, 2010; Willis, Pointon, O’Meara, McCarthy, \& Jensen, 2009). However, a unique finding from this study showed that many participants applied for work with two or three different ambulance services, and thus are willing to re-establish themselves in a new location, which differs from the extant literature (O'Meara, Tourle, Madigan, \& Lighton, 2012; Waxman \& Williams, 2006).

The post-formal professional socialization phase was confirmed as relevant to the paramedic context in this study. Interns, as employees, were introduced to the command and control management style (Lazarsfeld-Jensen et al., 2011) and a protocol driven modus operandi culture of ambulance services. They encountered marginalization (Boychuk Duchscher \& Cowin, 2004) as they made the transition from the orientation program to the on-road environment, and varying experiences were reported while trying to adjust to the micro-cultures at station level. The presence of a honeymoon phase was evident, which confirms similar findings to the literature inrelation to nursing professionals (Kramer, 1974). Also apparent was the pressure to conform to workplace routines and master clinical skills to fit in. The importance placed on workplace values and behaviors necessary to be accepted on station were evident, both positive and negative. For example, positive values and behaviors included being prepared, such as checking vehicles and equipment, whilst negative values and behaviors included being pessimistic and disparaging of management and communication staff. From the results, it was apparent that there is little consistency between ambulance services in relation to the structure of internship years. The lack of formalized resilience training for new ambulance staff was also highlighted as an important finding in this study.

Despite the initial transition challenges, and being marginalized by the ambulance culture, many reported having increased levels of confidence toward the end of the internship year. By this stage, most interns had potentially encountered a variety of ambulance work (Lazarsfeld-Jensen et al., 2011), leading to an increase in one's self confidence to perform the role of a paramedic intern. Alternatively, by this stage, interns had possibly achieved skills and routine mastery (Devenish et al., 2014; Kramer, 1974), which has been reported in the literature as the key to obtaining workplace acceptance.

A new professional socialization phase, the post-internship phase, was deemed necessary as the three stage model of professional socialization tested in this study did not adequately address the experiences of participants 
making the transition from interns to qualified (or registered) paramedics (Devenish et al., 2014). Within other health fields, such as nursing, a graduate is a registered nurse after completing their nursing degree. However, paramedic graduates are viewed as "paramedic interns" or "probationary paramedics" until they have finished their internship year. Thus the profession bestows the "qualified paramedic" title on an individual, which might be a remnant of the old vocational apprenticeship in-house style of training previously favored by ambulance services. During the post-internship phase, an adjustment to the added responsibilities of the paramedic role was required, and role complexities were encountered such as training new staff, and being the senior clinician on the ambulance despite having self-doubt in relation to their own abilities. The study highlighted the presence of a lack of mentor training, and that many qualified paramedics used mentoring styles they had encountered as new staff, which were not necessarily nurturing. During the post-internship phase, qualified paramedics reflected on the socialization journey and attempted to make sense of the reality of paramedic practice, which did not necessarily reflect their anticipatory preconceptions or the hidden curriculum encountered during their university studies.

From these findings, a model of paramedic professional socialization (Figure 6) has been developed. The model has been built on the anticipatory, formal and post-formal phases of professional socialization (Devenish et al., 2012; Devenish et al., 2014; Devenish et al., 2010; Higgs, 2013; Cant \& Higgs, 1999; Lamdin, 2006; Shuval \& Adler, 1977), and includes a new fourth phase specific to the paramedic context. Phase one relates to the formation of preconceptions during the anticipatory phase of professional socialization. Phase two is concerned with the learning and development stage which occurs during the formal phase of professional socialization.

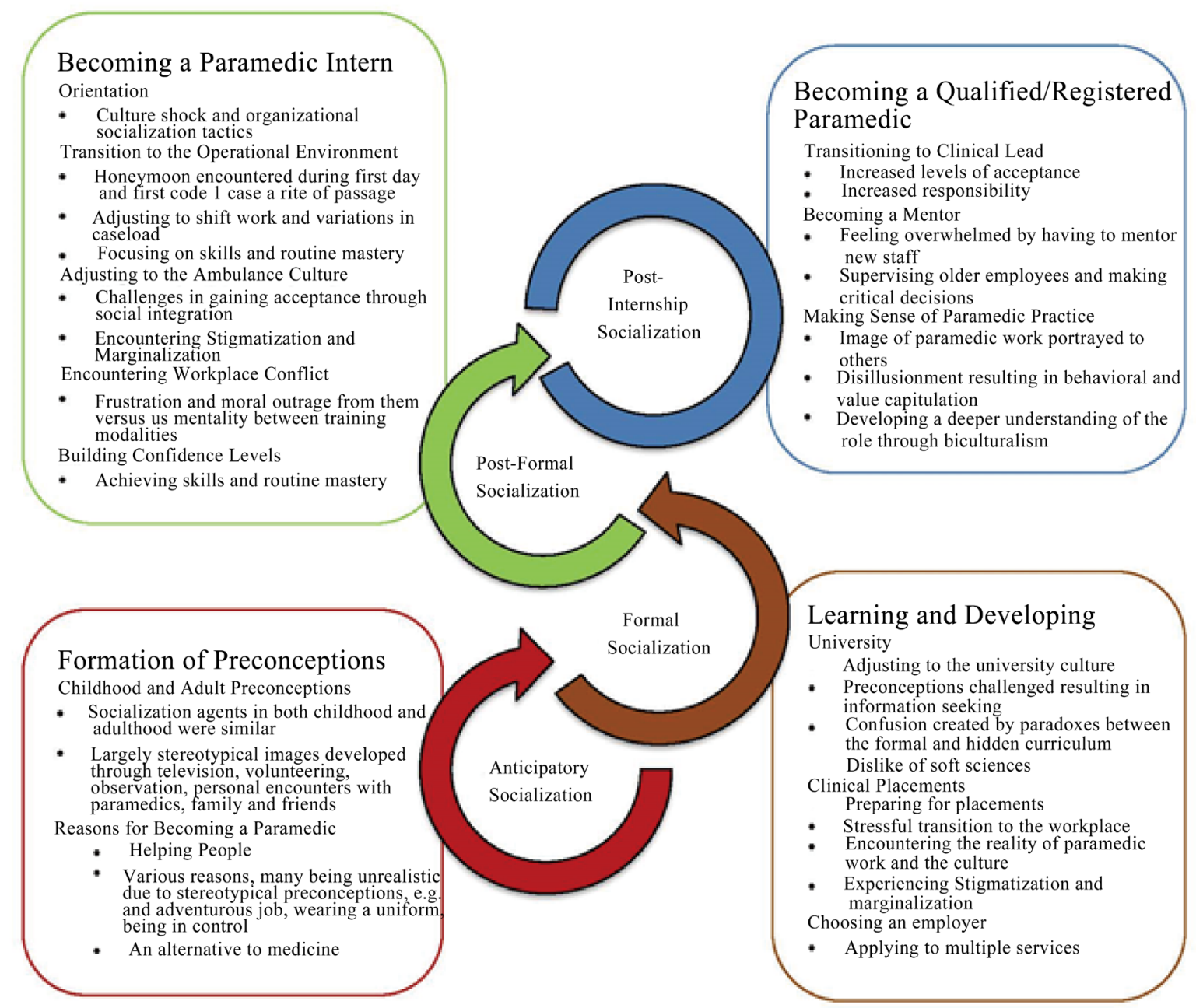

Figure 6. A model of paramedic professional socialization. 
Phase three describes the experiences of people making the transition from university student to practicing paramedic intern during the post-formal phase of professional socialization. The fourth phase or post-internship phase identifies the experiences of people making the transition from paramedic intern to qualified paramedic.

\section{Limitations of This Study and Areas for Further Research}

In this study we used qualitative methods to study the experiences of 34 people as they made the transition from university students to practicing qualified (or registered) paramedics. Thus the study does not claim to represent the ambulance profession as a whole. The cross-sectional nature of this study might be viewed as a limitation, because participants were interviewed at different point throughout the professional socialization process. A longitudinal study was not achievable due the constraints of time and resources.

Several areas for further study have arisen from this research. Further research is needed in relation to the structure of paramedic internship programs to reflect best practice. The paramedic hidden curriculum also needs further research in relation to how this reflects the reality of paramedic practice, and the extent to which the hidden curriculum contributes to the reality shock encountered by graduates making the transition to the on-road environment.

\section{Conclusion}

We used a three phase professional socialization model in this study to explore the professional socialization of university educated paramedics. To date the professional socialization of paramedics has been a largely neglected area of research. Although the anticipatory, formal and post-formal phases were confirmed to be relevant to the paramedic context, an additional phase, the post-internship phase of paramedic professional socialization was deemed to be necessary in better explaining the professional socialization of paramedics. Unlike many other health professions, the paramedics who took part in this study were required to complete an internship year before becoming qualified (or registered). The four phased model may assist ambulance services, educators and students to predict the trajectory of professional socialization of university educated paramedics and thus ease their transition into the workplace.

\section{Acknowledgements}

The authors wish to thank Queensland University of Technology and the Australian and New Zealand College of Paramedicine for funding this research study.

\section{References}

Anderson, B., \& Bell, J. (1998). Occupational Therapy: Its Place in Australia's History. Sydney: Association of Occupational Therapists.

Balon-Rotheram, A. (2003). The Development of Professional Qualifications for Paramedics at Victoria University. Journal of Emergency Primary Health Care, 1, 1 p.

Battersby, D. (1993). Collaboration between the Ambulance Service of New South Wales and Charles Sturt University: A Background Paper, April 1993. Wagga Wagga: Charles Sturt University

Becker, H. S., Hughes, E. C., Geer, B., \& Strauss, A. L. (1961). Boys in White: Student Culture in Medical School. Toronto: University of Chicago Press.

Boychuk Duchscher, J. E. (2008). A Process of Becoming: The Stages of new Nursing Graduate Professional Role Transition. Journal of Continuing Education in Nursing, 39, 441-450. http://dx.doi.org/10.3928/00220124-20081001-03

Boychuk Duchscher, J. E. (2009). Transition Shock: The Initial Stage of Role Adaptation for Newly Graduated Registered Nurses. Journal of Advanced Nursing, 65, 1103-1113. http://dx.doi.org/10.1111/j.1365-2648.2008.04898.x

Boychuk Duchscher, J. E. (2012). From Surviving to Thriving: Navigating the First Year of Professional Nursing Practice. Saskatoon: Nursing the Future.

Boychuk Duchscher, J. E., \& Cowin, L. S. (2004). The Experience of Marginalization in New Nursing Graduates. Nursing Outlook, 52, 289-296. http://dx.doi.org/10.1016/j.outlook.2004.06.007

Boyle, M., Williams, B., Cooper, J., Adams, B., \& Alford, K. (2008). Ambulance Clinical Placements—A Pilot Study of Students' Experience. BMC Medical Education, 8, 1-6. http://dx.doi.org/10.1186/1472-6920-8-19

Carney, C. J. (1999). Prehospital Care-A UK Perspective. British Medical Bulletin, 55, 757-766. 
http://dx.doi.org/10.1258/0007142991902763

Charmaz, K. (2006). Constructing Grounded Theory: A Practical Guide Through the Qualitative Analysis. Los Angeles, CA: Sage.

Charmaz, K. (2012). The Power and Potential of Grounded Theory. Medical Sociology Online, 6, 2-15.

Chipchase, L. S., Galley, P., Gwen, J., McMeeken, J. M., Refshauge, K., Nayler, M., \& Write, A. (2006). Looking Back at 100 Years of Physiotherapy Education in Australia. Australian Journal of Physiotherapy, 52, 3-7.

http://dx.doi.org/10.1016/S0004-9514(06)70055-1

Clark, S. (2009). Interprofessional Education: How Do We Teach It? Journal of Paramedic Practice, 1, 385-386.

COAG Health Council (2015). Communique. 6 November 2015. (Press release)

Conrad, P. (1988). Learning to Be a Doctor: Reflections on Recent Accounts of the Medical School Years. Journal of Health and Social Behaviour, 29, 323-332. http://dx.doi.org/10.2307/2136866

Coombs, R. H. (1978). Mastering Medicine: Professional Socialization in Medical School. New York: Free Press.

Davis, F., \& Olesen, V. (1964). Baccalaureate Students’ Images of Nursing. Nursing Research, 13, 8-15. http://dx.doi.org/10.1097/00006199-196401310-00004

Devenish, S. (2014). Experiences in Becoming a Paramedic: A Qualitative Study Examining the Professional Socialsiation of University Qualified Paramedics. Ph.D. Thesis, Brisbane: Queensland University of Technology.

Devenish, S., Clark, J. M., Fleming, M. L., \& Loftus, S. (2012). The Professional Socialization of Paramedics: The Transition from University Student to Practising Paramedic. In Qualitative Health Research 2012, Conference Abstracts: Presentations. International Journal of Qualitative Methods, 11, 784-785.

Devenish, S., Clark, M., \& Fleming, M. (2014). The Professional Socialization of Paramedics: The Transition from Intern to Qualified Paramedic. Australasian Journal of Paramedicine, 11, 24.

Devenish, S., Clark, M., Fleming, M., \& Loftus, S. (2011). The Professional Socialization of Paramedics: University and Its Role in the Socialization Process. Proceedings of the Trauma on the Border Conference, Tweed Heads, 1-2 April.

Devenish, S., Clark, M., Fleming, M. L., \& Loftus, S. (2010). The Professional Socialization of Paramedics: University and Its Role in the Socialization Process. Journal of Emergency Primary Health Care, 3.

Dey, I. (1993). Qualitative Data Analysis: A User Friendly Guide for Social Science. London: Routledge. http://dx.doi.org/10.4324/9780203412497

Dinmohammadi, M., Peyrovi, H., \& Mehrdad, N. (2013). Concept Analysis of Professional Socialization in Nursing. Nursing Forum, 48, 26-34. http://dx.doi.org/10.1111/nuf.12006

Donaghy, J. (2008). Higher Education for Paramedics—Why? Journal of Paramedic Practice, 1, 31-35. http://dx.doi.org/10.12968/jpar.2008.1.1.42030

du Toit, D. (1995). A Sociological Analysis of the Extent and Influence of Professional Socialization on the Development of a Nursing Identity among Nursing Students at Two Universities in Brisbane, Australia. Journal of Advanced Nursing, 21, 164-171. http://dx.doi.org/10.1046/j.1365-2648.1995.21010164.x

Emms, C. (2010). Paramedic Training and Higher Education: A Natural Progression? Journal of Paramedic Practice, 2, 529-533. http://dx.doi.org/10.12968/jpar.2010.2.11.80046

Fawcett, M., \& McCall, M. (2008). Paramedics for the Real World-First Graduates from the Queensland University of Technology. Australasian Journal of Paramedicine, 6, Number 7.

Finkelstein, L. M., Kulas, J. T., \& Dages, K. D. (2003). Age Differences in Proactive Newcomer Socialization Strategies in Two Populations. Journal of Business Psychology, 17, 473-501. http://dx.doi.org/10.1023/A:1023400201387

Gerrish, K. (1990). Fumbling Along. Nursing Times, 86, 35-37.

Gerrish, K. (2000). Still Fumbling Along? A Comparative Study of the Newly Qualified Nurse’s Perception of the Transition from Student to Qualified Nurse. Journal of Advanced Nursing, 32, 473-480. http://dx.doi.org/10.1046/j.1365-2648.2000.01498.x

Goode, W. J. (1960). Encroachment, Charlatanism and the Emerging Profession: Psychology, Sociology and Medicine. American Sociological Review, 25, 902-965.

Gregory, P. (2006). Training Emergency Care Practitioners: BSc Degree. Australasian Journal of Paramedicine, 4, Number 5.

Haas, J., \& Shaffir, W. (1987). Becoming Doctors: The Adaption of a Cloak of Competence. Greenwich: Jai Press.

Hafferty, F. (1988). Cadaver Stories and the Emotional Socialization of Medical Students. Journal of Health and Social Behaviour, 29, 344-356. http://dx.doi.org/10.2307/2136868

Hallikainen, J., Vaisanen, O., Rosenberg, P. H., Silfvast, T., \& Niemi-Murola, L. (2007). Interprofessional Education of 
Medical Students and Paramedics in Emergency Medicine. Acta Anaesthesiologica Scandinavica, 51, 372-377. http://dx.doi.org/10.1111/j.1399-6576.2006.01224.x

Henderson, T. (2012). Influence of Life Experience on Undergraduate Paramedic Students' Placement. Journal of Paramedic Practice, 4, 585-592. http://dx.doi.org/10.12968/jpar.2012.4.10.585

Higgs, J. (2013). Professional Socialization. In S. Loftus, T. Gerzina, J. Higgs, M. Smith, \& E. Duffy (Eds.), Educating Health Professionals: Becoming a University Teacher (pp. 83-92). Boston, MA: Sense Publishers. http://dx.doi.org/10.1007/978-94-6209-353-9_8

Cant, R., \& Higgs, J. (1999). Professional Socialization in Educating Beginning Practitioners. In J. Higgs, \& H. Edwards (Eds.), Challenges for Health Professional Education (pp. 46-51). Melbourne: Butterworth-Heinemann.

Howkins, E. J., \& Ewens, A. (1999). How Students Experience Professional Socialization. International Journal of Nursing Studies, 36, 41-49. http://dx.doi.org/10.1016/S0020-7489(98)00055-8

Huot, K. (2013). Transition Support for New Graduate Paramedics. Master's Thesis, Victoria, BC: Royal Roads University.

Jablin, F. M. (2001). Organizational Entry, Assimilation and Disengagement/Exit. In F. M. Jablin, \& J. Putnam (Eds.), The New Handbook of Organizational Communication: Advances in Theory, Research and Methods (pp. 732-818). Thousand Oaks, CA: Sage. http://dx.doi.org/10.4135/9781412986243

Jones, G. R. (1986). Socialization Tactics, Self Efficacy and Newcomers Adjustment to Organizations. Academy of Management Journal, 29, 262-279. http://dx.doi.org/10.2307/256188

Kilner, T. (2004). Educating the Ambulance Technician, Paramedic, and Clinical Supervisor: Using Factor Analysis to Inform the Curriculum. Emergency Medicine Journal, 21, 379-385. http://dx.doi.org/10.1136/emj.2003.009605

Kramer, M. (1974). Reality Shock: Why Nurses Leave Nursing. St Louis: C.V Mosby Company.

Kramer, M. W. (2010). Organizational Socialization: Joining and Leaving Organizations. Cambridge: Polity.

Lamdin, R. J. (2006). The Professional Socialization of Medical Students through the Preclinical to Clinical Transition. Ph.D. Thesis, Auckland: The University of Auckland.

Larsen, R. (2013). Proposed South Australian Paramedic Title Protection Legislation. http://www.paramedics.org.au/content/2013/10/PA-Member-Update-South-Australia-Paramedic-Title-Protect\%E2\%80\% A6.pdf

Lazarsfeld-Jensen, A., Bridges, D., \& Loftus, S. (2011). Transitions: Command Culture and Autonomous Paramedic Practice. https://www.researchgate.net/publication/269279385_TRANSITIONS_Command_culture_and_autonomous_paramedic_p ractice

Lord, B. (2003). The Development of a Degree Qualification for Paramedics at Charles Sturt University. Australasian Journal of Paramedicine, 1, Number 13.

Lord, B., McCall, L., \& Wray, N. (2009). Factors Affecting the Education of Pre-Employment Paramedic Students during the Clinical Practicum. Australasian Journal of Paramedicine, 7, Number 3.

Maclellan, D., Ly, D. L., \& Gingras, J. (2011). Professional Socialization in Dietetics: A Review of the Literature. Canadian Journal of Dietetic Practice and Research, 72, 37-42. http://dx.doi.org/10.3148/72.1.2011.37

Mallinson, T. (2011). The Dangers of Starting Interprofessional Learning Too Soon. Nurse Educator, 36, 1. http://dx.doi.org/10.1097/NNE.0b013e3182001c4f

McDonell, A. H. (1994). University Education for Ambulance Officers and Paramedics, Submissions to Health and Community Services, Acute Health Services. Preston: Ambulance Professional Education Lobby.

Merton, R. K., Reader, G. G., \& Kendall, P. L. (1957). The Student Physician: Introductory Studies in the Sociology of Medical Education. Cambridge, MA: Harvard University Press. http://dx.doi.org/10.4159/harvard.9780674366831

Michau, R., Roberts, S., Williams, B., \& Boyle, M. (2009). An Investigation of Theory-Practice Gap in Undergraduate Paramedic Education. BMC Medical Education, 9, 1-7. http://dx.doi.org/10.1186/1472-6920-9-23

Morrison, E. R. (1995). Information Usefulness and Acquisition during Organizational Encounter. Management Communication Quarterly, 9, 131-155. http://dx.doi.org/10.1177/0893318995009002001

Morrison, E. W. (1993). Newcomer Information Seeking: Exploring Types, Modes, Sources. Academy of Management Journal, 36, 557-590. http://dx.doi.org/10.2307/256592

O’Brien, K., Moore, A., Dawson, D. A., \& Hartley, P. R. (2014). An Australian Story: Paramedic Education and Practice in Transition. Australasian Journal of Paramedicine, 11, Article 4.

O’Meara, P. (2011). So How Can We Frame Our Identity? Journal of Paramedic Practice, 3, 57-57. http://dx.doi.org/10.12968/jpar.2011.3.2.57

O’Meara, P. (2012). Paramedics Marching towards Professionalism. Australasian Journal of Paramedicine, 7, Number 1. 
O’Meara, P., \& Furness, S. (2013). Education in the Emerging Professions. In S. Loftus, T. Gerzina, J. Higgs, M. Smith, \& E. Duffy (Eds.), Educating Health Professionals: Becoming a University Teacher (pp. 93-102). Boston, MA: Sense Publishers. http://dx.doi.org/10.1007/978-94-6209-353-9_9

O’Meara, P., Tourle, V., Madigan, V., \& Lighton, D. (2012). Getting in Touch with Paramedic Student Career Intentions. Health Education Journal, 71, 376-385. http://dx.doi.org/10.1177/0017896911406962

Owens, D., Turjanica, M. A., Scanion, M. W., Williamson, M., \& Facteau, L. (2001). New Graduate RN Internship Program, a Collaborative Approach for System Wide Integration. Journal of Nurses in Staff Development, 17, 144-150. http://dx.doi.org/10.1097/00124645-200105000-00010

Pitkala, K., \& Mantyranta, T. (2003). Professional Socialization Revised: Medical Students’ Own Conceptions Related to Adoption of the Future Physicians Role-A Qualitative Study. Medical Teacher, 25, 155-160. http://dx.doi.org/10.1080/0142159031000092544

Raynovich, W. (2006). Transition of a Vocational-Technical Program to an Academic Degree-Franting Program: An Action Research Case Study. Ph.D. Thesis, Albuquerque, NM: The University of New Mexico.

Ross, L. (2012). Interpersonal Skills Education for Undergraduate Nurses and Paramedics. Journal of Paramedic Practice, 4 , 655-661. http://dx.doi.org/10.12968/jpar.2012.4.11.655

Saldana, J. (2013). The Coding Manual for Qualitative Researchers (2nd ed.). London: Sage.

Sheather, R. (2009). Professionalism. In P. O’Meara, \& C. Grbich (Eds.), Paramedics in Australia; Contemporary Challenges of Practice (pp. 45-60). Frenchs Forest: Pearson Education Australia.

Shuval, J. T., \& Adler, I. (1977). Processes of Continuity and Change during Socialization for Medicine in Israel. Journal of Health and Social Behavior, 18, 112-124. http://dx.doi.org/10.2307/2955376

Sibson, L., \& Mursell, I. (2010). Mentorship for Paramedic Practice: Bridging the Gap. Journal of Paramedic Practice, 2 , 270-274. http://dx.doi.org/10.12968/jpar.2010.2.6.48809

Simpson, I. H. (1967). Patterns of Socialization into Professions: The Case of Student Nurses. Sociological Inquiry, 37, 4754. http://dx.doi.org/10.1111/j.1475-682X.1967.tb00637.x

Stone, J., \& Cooper, J. (2001). A Self-Standards Model of Cognitive Dissonance. Journal of Experimental Social Psychology, 37, 228-243. http://dx.doi.org/10.1006/jesp.2000.1446

Tanner, K., Knights, A., \& Strange, B. (2010). The Foundations of Paramedic Science and Beyond. Journal of Paramedic Practice, 2, 384-388. http://dx.doi.org/10.12968/jpar.2010.2.8.78014

Thibodeau, R., \& Aronson, E. (1992). Taking a Closer Look: Reasserting the Role of the Self-Concept in Dissonance Theory. Personality and Social Psychology Bulletin, 18, 591-602. http://dx.doi.org/10.1177/0146167292185010

Thompson, S. (2015). The Perceived Concerns of Newly Qualified Paramedics Commencing Their Careers: A Pilot Study. Journal of Paramedic Practice, 7, 74-78. http://dx.doi.org/10.12968/jpar.2015.7.2.74

Thornton, R., \& Nardi, R. M. (1975). The Dynamics of Role Acquisition. American Journal of Psychology, 80, 870-885. http://dx.doi.org/10.1086/225897

Tradewell, G. (1996). Rites of Passage: Adaptation of Nursing Graduates to a Hospital Setting. Journal of Nursing Staff Development, 12, 183-189.

Tryssenaar, J. (1999). The Lived Experience of Becoming an Occupational Therapist. British Journal of Occupational Therapy, 62, 107-112. http://dx.doi.org/10.1177/030802269906200304

Tryssenaar, J., \& Perkins, J. (2001). From Student to Therapist: Exploring the First Year of Practice. The American Journal of Occupational Therapy, 55, 19-27. http://dx.doi.org/10.5014/ajot.55.1.19

Van Maanen, J. (1976). Breaking in: Socialization to Work. In R. Dubin (Ed.), Handbook of Work, Organization and Society (pp. 67-130). Chicago, IL: Rand McNally College Publishing Co.

Van Maanen, J. (1978). People Processing: Strategies of Organizational Socialization. Organizational Dynamics, 7, 18-36. http://dx.doi.org/10.1016/0090-2616(78)90032-3

Waxman, A., \& Williams, B. (2006). Paramedic Pre-Employment Education and the Concerns of Our Future: What Are Our Expectations? Australasian Journal of Paramedicine, 4, Number 4.

Whitmore, D., \& Furber, R. (2006). The Need for a Professional Body for UK Paramedics. Australasian Journal of Paramedicine, 4, Number 10.

Williams, B., \& Boyle, M. (2008). The Use of Interactive Wireless Keypads for Interprofessional Learning Experiences by Undergraduate Emergency Health Students. International Journal of Education and Development Using ICT, 4.

Williams, B., Brown, T., \& Boyle, M. (2012). Construct Validation of the Readiness for Interprofessional Learning Scale: A Rasch and Factor Analysis. Journal of Interprofessional Care, 26, 326-332.

http://dx.doi.org/10.3109/13561820.2012.671384 
Williams, B., Brown, T., \& Winship, C. (2012). The Mismatch between Perceived and Preferred Expectations of Undergraduate Students. The Internet Journal of Allied Health Sciences and Practice, 10.

Williams, B., McCook, F., Brown, T., Palmero, C., McKenna, L., Boyle, M., Scholes, R., French, J., \& McCall, L. (2012). Are Undergraduate Health Care Students Ready for Interprofessional Learning? A Cross-Sectional Attitudinal Study. The Internet Journal of Allied Health Sciences and Practice, 10, 1-11.

Williams, J., Devenish, S., \& Stephens, J. (2012). Qualitative Research in Ambulance Services: The Reality of Practice. Paper presented at the Qualitative Health Research Conference, Montreal, Canada. International Journal of Qualitative Methods, 11, 800-822.

Willis, E., Pointon, M. T., O’Meara, P., McCarthy, M. C., \& Jensen, M. A. L. (2009). Paramedic Education: Developing Depth through Networks and Evidence-Based Research.

http://www.olt.gov.au/system/files/resources/DS7-616\%20Paramedic\%20education\%20March\%202009.pdf

Willis, E., Williams, B., Brightwell, R., O’Meara, P., \& Pointon, T. (2010). Road-Ready Paramedics and the Supporting Sciences Curriculum. Focus on Health Professional Education: A Multi-disciplinary Journal, 11, 1-13.

Woollard, M. (2009). Professionalism in UK Paramedic Practice. Australasian Journal of Paramedicine, 7, Number 9.

Wray, N., \& McCall, L. (2009). They Don’t Know Much about Us: Educational Reform Impacts on Students’ Learning in the Clinical Environment. Advances in Health Sciences Education: Theory and Practice, 14, 665-676. http://dx.doi.org/10.1007/s10459-008-9146-y 